\title{
LA TRAMITACIÓN SUBJETIVA DE LA INTOLERANCIA EN UNA EXPERIENCIA DE GRUPO DE ACONTECIMIENTO
}

\section{THE SUBJECTIVE PROCESSING OF INTOLERANCE IN AN EVENT GROUP EXPERIENCE}

\begin{abstract}
Mario Orozco Guzmán', Flor de María Gamboa Solís ${ }^{2}$, David Pavón-Cuéllar ${ }^{3}$
'Doctorado en Psicología. Profesor-Investigador de la Facultad de Psicología de la Universidad Michoacana de San Nicolás de Hidalgo. Morelia, Michoacán, México.orguzmo@yahoo.com.mx ${ }^{2}$ Doctorado en Estudios de Género. Profesora-Investigadora de la Facultad de Psicología de la Universidad Michoacana de San Nicolás de Hidalgo. Morelia, Michoacán, México. florgamboa@yahoo.com

${ }^{3}$ Doctorado en Filosofía y doctorado en Psicología. Profesor-Investigador de la Facultad de Psicología de la Universidad Michoacana de San Nicolás de Hidalgo. Morelia, Michoacán, México. davidpavoncuellar@gmail.com
\end{abstract}

RESUMEN I Se propone una modalidad de intervención clínico-grupal denominada "Grupo de Acontecimiento" para el tratamiento de situaciones de intolerancia. El procesamiento de este tipo de experiencias implica un trabajo de reescritura para la integración simbólica de las mismas. La vivencia de intolerancia pasa por la palabra y significación comprometida de los otros. Los testimonios exponen la variación interpretativa de los discursos y la repercusión del acontecimiento como impresión decisiva y trascendental en la historia de un sujeto. La modificación testimonial responde a la escucha y lectura que los otros desplieguen de los sentidos que se anuden a la escritura del acontecimiento.

Palabras clave: Intolerancia, grupo, acontecimiento, testimonio, violencia.

\begin{abstract}
I A psychoanalytical clinical group intervention modality called "Event Group" is proposed for the treatment of situations of intolerance. The processing of this kind of experiences implies a work of rewriting for their symbolic integration. The experience of intolerance passes through both the word and the committed meaning from others. The subject's testimony of the situations of intolerance exposes the interpretive variation of discourses and the effects of the event understood as a decisive and transcendental impression in the history of a subject. The testimonial modifications respond to the listening and reading that the others deploy of the senses that tie to the writing of the event.
\end{abstract}

Keywords: intolerance, group, event, testimony, violence. 


\section{PREMISAS}

El presente trabajo expone una propuesta de clínica psicoanalítica grupal en torno a situaciones de intolerancia. Como dispositivo analítico, esta propuesta confiere el peso determinante de la dinámica a la palabra en una apertura para poner a disposición de los otros, experiencias que incidieron a la manera de un corte en la historia subjetiva. La experiencia de intolerancia pone a prueba la capacidad del sujeto para la asimilación simbólica de su aparición inusitada. El efecto de conmoción es indudable, así como su demarcación. El sujeto queda marcado por dicha experiencia que pone al límite sus recursos de comprensión imaginaria y de engranaje simbolizante.

La propuesta de Grupo de Acontecimiento hace pensar en el abordaje freudiano del trauma como suceso que exige una rememoración puesta en palabras. La misma propuesta remite simultáneamente a posibilidades de encontrar en el otro, en los otros, en la alteridad de la escucha, diferentes acercamientos a su significación. El grupo extiende su red de lenguaje y el lenguaje encuentra en el grupo ramificación de aperturas de sentido para el ejercicio testimonial.

Apostar por el grupo para el abordaje de las intolerancias supone una exigencia ética del empeño en la diferenciación responsable. También implica proponer un modo de apelar al otro y a los otros, a su saber y a sus preguntas, a su perplejidad y sorpresa. Es así como se busca descifrar y quizás superar las posiciones contemporáneas de autismo social pletórico de "identificaciones miméticas" (Milmaniene, 2010, p. 57). Estas posiciones, afiliadas al conformismo y al confort de un desenfrenado consumo de goce, son desafiadas por la diferencia y por la otredad en cuyo reconocimiento se basa una clínica psicoanalítica grupal como la que aquí se propone.

La tolerancia llevada al límite

El acontecimiento es una cuestión de drama en discurso, de un drama entramado y enredado en decires y dichos. Es en el ámbito discursivo en el que todo le acontece al sujeto (Pavón-Cuéllar, 2013). Como bien lo notaba Lacan (1953/1999a), el acontecimiento requiere del "escenario de lenguaje" como primera condición de posibilidad (pp. 258259).

Las palabras constituyen lo que acontece. Del acontecimiento se habla. Y se habla mucho. Se repite discursivamente en tanto sitúa un cambio radical en la historia del sujeto. Hay un decir incesante en relación al acontecimiento y en su constitución misma. Otros decires desembocan en este acontecimiento en el que Freud (1893-95/2000) ayudó a rastrear algo del inconsciente que se ordenaba y se desplegaba en las palabras.

Para llegar a pensar el acontecimiento como pauta y apertura discursiva del inconsciente, Freud (1893-95/2000) tuvo que inscribirlo antes en algo traumático, indecible, tal vez ya indisociable de las palabras, pero que no conseguía fácilmente abrirse paso en el lenguaje. La estructura de la memoria dependía entonces de las vías que se recorrían para intentar acceder al acontecimiento cifrado en un episodio de seducción abusiva. La estructura mnémica resultaba ser de "triple estratificación" ( $p$. 293): 1) una memoria de ordenamiento cronológico en la que los recuerdos se irían exhumando, de uno en uno, desde el más inmediato hasta el más remoto; 2) una memoria de organización concéntrica en función de una resistencia que se intensificaría a medida que se acerca a lo que se denomina el "núcleo patógeno" (p. 294); 3) una memoria acorde al contenido del pensamiento, en la que los recuerdos se ramificarían en virtud de sus enlaces lógicos, de tal modo que sería el acontecimiento el que dictaría las modalidades diversas del rememorar.

El acontecimiento es lo que intenta recordarse, lo que insiste a través de lo que se recuerda, pero también lo que resiste a su rememoración. Una de las razones de tal resistencia es lo intolerable que puede resultar lo acontecido para quien busca recordarlo. Al acontecimiento subyace así la intolerancia y sus condiciones y niveles de impacto. Es aquí en donde se inserta nuestra propuesta metodológica de trabajo clínico grupal. Nuestra 
propuesta, en efecto, interroga a los participantes del grupo en relación a una puesta a prueba de su capacidad de tolerancia. El acontecimiento pone a prueba su palabra, los límites de la palabra y las posibilidades de hacer de sus decires operación grupal.

La recién mencionada condición límite de la tolerancia es plasmada en sentencias del pensamiento estoico del emperador romano Marco Aurelio (2000):

Todo lo que acontece, sucede en tal conformidad, que eres naturalmente capaz de aguantarlo o naturalmente incapaz de aguantarlo. Ahora bien: si te acontece algo que seas hombre para soportarlo, no te irrites; antes bien, sopórtalo según la medida de tus fuerzas. Si, por el contrario, es algo que no eres capaz de soportar naturalmente, no te irrites tampoco, pues acabaría por consumirte (p. 146).

En otras palabras, de lo que uno aguanta y de lo que uno no aguanta está hecho el acontecimiento. Es indispensable indagar el precio de lo que se ha aguantado, es decir, los costos y efectos de la intolerancia. Pero igualmente hay costos y efectos de lo que no pudo aguantarse. Se recomienda no irritarse; sin embargo, aunque el sujeto no se irrite, su cuerpo o una parte de éste puede hacerlo en su lugar. Es quizás lo que ocurre con el "intestino irritable" o "colon irritable", como se conoce mejor a ese llamado "síndrome del mal defecar", del preso de dolor y distención abdominal: condición crónica y recidivante que en la actualidad parece estar aquejando a un buen número de mujeres más que de hombres, y que se asocia en su causalidad a factores psicológicos (Vinaccia, Fernández, Amador, Tamayo y Vásquez, 2005). Se trataría, por lo tanto, de alteraciones de orden subjetivo. Podríamos decir que el intestino irritable es el costo de lo que el sujeto no pudo aguantarse y que más mujeres resulten afectadas por esta condición no es ninguna sorpresa, dado que, si algo les ha sido tajantemente prohibido y censurado en nuestra cultura, es enojarse: irritarse, precisamente. Tolerancia al límite. Las mujeres en todo el mundo están sujetas a "sistemas de modestia" (Copjec, 2006, p. 134) que les imponen recato y mesura, y a los que subyace la creencia patriarcal milenaria de que hay algo en ellas que nunca puede ser controlado suficientemente. Entonces a callarlas, a cubrirlas de velos y túnicas, como sucede en las sociedades islámicas, y empujarlas a que traten los costos de no aguantar el peso de la modestia oprimiendo su colon, con un gastroenterólogo.

¿Cómo aguantar lo que parece inaguantable? Para los seguidores de la doctrina estoica es fundamental mantenerse impasible e indiferente ante el vendaval de los sucesos. Marco Aurelio (2000), por ejemplo, se cuestiona respecto a una situación llevada al límite: "¿Qué hay en esto que no sea soportable y llevadero?" (p. 124). Sin embargo, el yo de orden narcisista, presuntamente aguantador, flaquea inevitablemente. Hay cosas que no aguanta. No dispone de palabras para aguantar y soportar cierto tipo de acontecimientos. La palabra le falla - le falta para tolerar algunas experiencias. El yo en lo imaginario parece portentoso, omnipotente, plenamente grande y fuerte, pero en lo real está zaherido por su condición original de vulnerabilidad. El límite de la tolerancia es a menudo el límite de la palabra. Es destacable el hecho de que este límite de la palabra no sólo tenga que ver con una experiencia de angustia $u$ horror. Como lo ha mostrado Lacan (1960/1986), también la belleza impone un límite infranqueable a una palabra que debe oscilar, desesperada en su impotencia, entre la poesía cortesana y el prosaísmo sadiano. Es correlativo al gesto del discurso racional que debe reconocerse impotente ante algo como lo sublime en Kant (1790/1991). Vigarello (2004) evoca esta impotencia de la palabra resguardada en la fórmula "Yo no sé qué" (p. 68), cuyo registro es precisamente el del misterio. El sujeto no sabe qué le pasa, no sabe qué hacer, cómo nombrar una experiencia que desborda su capacidad de aguante $y$ tolerancia.

La intolerancia como situación límite, como prueba de aguante para un yo desdoblado en el narcisismo del poder soportar-todo y el real de la indefensión y el desvalimiento, también puede ofrecer la posibilidad de un cifrado discursivo, un cifrado estructural y escritural. Esto es un aspecto de lo que se propone con el dispositivo de Grupo de Acontecimiento: poner la experiencia de intolerancia en perspectiva de discurso, es decir, en la dimensión de la diversidad discursiva y de la intervención y participación de otros en el encuentro grupal. 
Una de las posibles perspectivas discursivas es la escritural, que puede ser testimonial, $y$, en este caso, tener algo de alcance liberador. Aunque la cura analítica no transite fundamentalmente por la escritura, se sabe que "los únicos instrumentos que sirven de vehículo al testimonio son escritos" (Lacan, 2001, p. 67). Recurramos a tres testimonios bien conocidos en los que se pone en evidencia el portento liberador de la escritura en condiciones de miedo: el de Ana Frank, el de Franz Kafka y el de Roland Barthes.

El destinatario imaginario de Ana Frank (2001), de nombre Kitty, es decisivo para que ella se atreva a decir: "Al escribir me libero de todo, mi pesar desaparece y mi valor renace" (p. 167). Mientras las SS y la Gestapo han sembrado persecución y el horror en poblaciones enteras de Europa, una incipiente adolescente hace de la escritura sostén de valoración y protección narcisista. En un momento socio-histórico en el que no hay salidas liberadoras, cuando "el terror reina en la ciudad" (p. 63) y "todo el mundo tiene miedo" (p. 63), una chica encuentra en la escritura una vía portentosa, omnipotente, mágica, de liberación: "al escribir, yo puedo concretarlo todo: mis pensamientos, mi idealismo, mis fantasías" (p. 68). La escritura parece ser también patrimonio de un orden narcisista que "nunca se resignará del todo" (Freud, 1913, p. 92) y que determina una sobrestimación y omnipotencia del acto mismo de escribir. Cuando parece resignado ante el miedo y el terror que domina todo y cerca todo, el sujeto encuentra en la palabra escrita, ya sea un soporte de no-resignación, o bien la posibilidad de poner otros signos por encima de los signos del terror: otros signos que, al tener destinatario transferencial, poseen destino social, además de la fuerza para alterarlo. Porque eso es lo que hacen las mujeres cuando escriben: alterar su destino social, que implica al mismo tiempo alterarse ellas mismas, no en el sentido patológico del término, como sinónimo de daño, sino en apego a su morfología latina, donde "alter", que significa "otro", alude a lo que cambia de estado, a una transformación subjetiva, al pasaje a otra forma de ser otro(a).

Desde Virginia Woolf (1929/2012) y Simone de Beauvoir (1949/20012) hasta las feministas francesas de mediados de los setenta y ochenta, Luce Irigaray (1977/2009), Hélène Cixous y Catherine
Clément (1986), la escritura de las mujeres ha sido entendida como un medio de emancipación. La escritura "proporciona una experiencia anticipadora de la liberación" (Flax, 1990, p. 292). Es un soporte de no-resignación, como se apuntó anteriormente, al Destino Social que mayormente han tenido que soportar las mujeres en razón de la fuerza procreativa dotada naturalmente a su cuerpo: la maternidad. No todas las mujeres desean ser madres, por insorportable que parezca reconocerlo. Representando lo "Otro", la diferencia en los planos filosóficos, sexual y psíquico según los sistemas falogocéntricos (Derrida, 1975), la mujer puede en y con la escritura apropiarse de su condición subalterna de otredad para alterarse, refigurarse y ser otra, y con ello, alterar la hegemonía del orden masculino. Yuxtaponer la "écriture féminine" (Cixous y Clément, 1986; Irigaray, 1977/2009) al discurso falocéntrico, como movimiento político de reivindicación de la diferencia, afirma la posibilidad de transformar el sistema de significación y su significado para que las mujeres puedan hablarse de ellas mismas, quebrando así las ausencias y silencios que la cultura occidental ha puesto sobre el placer/sexualidad femeninos. La escritura (literal y metafórica) de las mujeres inserta la especificidad femenina que rompe con el monopolio de la palabra y el pensamiento masculino y ratifica a la mujer "en algún lugar diferente al silencio, el lugar reservado para ella mediante lo simbólico" (Cixous y Clément, 1986, p. 93), habilitando a sus signos otros destinos sociales $y$ otras formas de ser mujer.

También la carta de Kafka (2011) a su padre es de tipo testimonial. Bajo el atroz despotismo del padre, el joven Kafka no tenía a su alcance la posibilidad de tomar la palabra y replicar. Se encontraba tan intimidado ante su padre que era incapaz de hablar delante de él. Le arrostra en sus cartas ese supuesto método educativo implementado por el padre y basado en un ejercicio de violencia verbal y en el empleo de la ironía. El daño del gesto amenazante del padre autoritario arraiga en el joven. Lo hace inseguro y vacilante en el uso de la palabra. Miedo y culpa se enlazan. Entonces, en estas condiciones de desamparo, resalta que alguien pueda decir: "En cierta forma cuando escribo estoy a salvo" (p. 52). La escritura aparece como instrumento de redención ante un padre que con su indiferencia ofendía su vocación de escritor. Vocación que hacía ilusionarse 
al joven Kafka con una autonomía respecto al dominio aplastante del padre.

Si bien es cierto que llega a verbalizarse lo que difícilmente se ha escrito o lo que en algún momento se llegue a escribir, también lo es el hecho de que se escriben cosas que nunca se han dicho o que quizás nunca se dirán:

Por supuesto, esto solamente era una ilusión, pues aún no tenía libertad. Mis escritos se referían a ti; en ellos anotaba las quejas que no me atrevía a decirte frente a frente, recargado sobre tu pecho (Kafka, 2011, p. 52).

Los escritos vehiculizan también algo de lo indecible. Los escritos son salvoconducto de una palabra empujada al silencio por un tribunal severo que materializa la presencia devastadora de un padre despótico. Los escritos permiten, por este sendero testimonial, hacer que se consiga "algo muy cercano a la verdad" (Kafka, 2011 , p. 76). Es decir, el que escribe le demanda a su propio escrito una misión y un compromiso: "conviértete en mi verdad". Petición y ruego de que ejerza de testimonio fehaciente de una verdad singular, aunque también evoque la función de un decir que hace transporte y plasmación de una verdad en lo concreto del escrito.

Roland Barthes (2009) en su Diario de Duelo insta a pensar otra de las posibilidades liberadoras de la escritura. Escribe este texto al día siguiente de la muerte de su madre de 84 años. Se refiere a esta muerte en tanto "acontecimiento, una a-ventura" (p. 61). En este sentido posee carácter movilizador, pues activa la palabra, pero también deja de ser acontecimiento y se presenta con "otra duración, amontonada, insignificante, no narrada, gris sin recurso: duelo verdadero insusceptible de una dialéctica narrativa" (p. 61).

El duelo no susceptible de ser dicho constituye el amontonamiento caótico del real. Constituye su densidad. Aun en ese caso, ìresiste a la escritura? Barthes reconoce que escribir no es tanto una funciónrecuerdo sino "para combatir el desgarramiento del olvido en cuanto que se anuncia absoluto" (Barthes, 2009 , p. 125). La escritura del duelo relativiza la desgarradura del olvido. Permite pensar lo definitivo de la muerte de alguien que parecía inmortal como la madre y como el propio yo estructuralmente narcisista:

Pensar, saber que mamá está muerta para siempre, completamente ('completamente' que sólo se puede pensar haciéndose violencia y sin que se pueda sostener largo tiempo este pensamiento), es pensar, letra por letra (literalmente, y simultáneamente) que yo también moriré para siempre y completamente." (Barthes, 2009, p. 131).

Las experiencias de pérdidas definitivas, irrevocables, absolutas y totales, que desgarran al sujeto, se subjetivizan "pieza por pieza" (Freud, 1915-17/2000, p. 243), palabra por palabra, letra por letra. Greiser (2012) se remite a lo que Lacan indicaba acerca de entender la clínica psicoanalítica "como lo real imposible de soportar. Cada analista tiene su propio insoportable" (p. 55). Cada sujeto tiene sus propios límites de soporte y tolerancia, y de soportar lo intolerable.

Una clínica del texto en grupo de acontecimiento.

En nuestra propuesta de trabajo clínico, hacer del acontecimiento insoportable texto, material de escritura, viene a ser una cuestión de lectura, pero también de grupo. Si es cuestión de grupo, o tarea grupal como diría Pichon-Rivière (1978), es porque el acontecimiento se lee al principio desde los otros, a partir de los otros. De este modo, su lectura, de entrada, se entrega a la diversidad.

La escritura, en sí misma, parece ser instrumento de cura. Ocurre lo mismo con el grupo. Hay, pues, un doble aspecto curativo en el desliz y en el deslizamiento de la palabra entre los componentes del grupo. El sujeto escucha el escrito de su acontecimiento dicho por otro hasta en dos ocasiones. Se apuesta por escuchar su drama leído por otro. Uno mismo, en una experiencia de a-ventura decisiva, es leído por la palabra del otro. La experiencia grupal exhorta a la amplificación del espectro de la escucha. Ya esa lectura del otro, ya esta participación del otro, en mi acontecimiento, hará efecto en la reescritura del mismo. ¿La lectura del otro hará posible algo de lo imposible, comenzar a soportar lo insoportable? 
Dice Malraux (1979) que "el peor sufrimiento está en la soledad que lo acompaña. Expresarlo también libera; pero pocas palabras son menos conocidas por los hombres que las de sus dolores profundos" (p. 147). La presencia del otro, su presencia de palabra que me lee, que lee uno de mis peores sufrimientos, puede tener algo de liberador. Siempre en ese desafío de la búsqueda de una "palabra que sea más fuerte que gozo" (p.105), de palabras, propias-ajenas que lean, esos dolores profundos e insoportables, esos dolores que parecen innombrables.

Se requiere que la palabra no se atasque en el goce masoquista ni se coagule de goce masoquista. A veces las palabras, más que ser liberadoras, resultan opresoras, corroídas por el goce masoquista. Hay palabras que se imponen violentamente o que imponen violencia:

El acto violento puede destruir lo simbólico, pero éste no opera sin violencia ya que implica la separación brutal entre nombre y cuerpo, memoria y carne. Es verdad que su violencia puede suceder en la emoción, el cambio, la creación; en el acontecimiento de ser (Sibony, 1998, p. 125).

Esta separación o des-anudamiento entre lo real y lo simbólico revela lo indecible de lo que pasa en el cuerpo, lo que la palabra no puede soportar ni nombrar del sufrimiento que lo desgarra o traspasa. Palabras heridas que naufragan a la deriva hasta que encuentran otra voz para purgar su goce.

El grupo de acontecimiento despliega los discursos de los componentes del grupo a través de un proceso asiduo de reescritura de las experiencias de intolerancia. Aquí "se trata menos de recordar que de rescribir la historia" (Lacan, 1981, p. 29). Cada momento de reescritura de la historia del acontecimiento, al diversificarlo en sus modalidades interpretativas, permite recordarlo de distintas maneras. El acontecimiento no se ciñe a una sola lectura y a una sola escritura. En particular, el sujeto en grupo se expone en su diversidad escritural y testimonial: corre el riesgo de que el otro, también como referente transferencial, lo lea y lea en su escritura algo más.
Como lo propone Lacan (1981), "debemos analizar la palabra por capas sucesivas, debemos buscar sus sentidos múltiples entre líneas" (p. 352). La búsqueda de los sentidos múltiples, tal como se entiende en nuestra propuesta de trabajo clínico, es algo en lo que se comprometen los componentes del grupo. La multiplicación del sentido remite a una escucha de abanico, de espectro amplio en el grupo, irreductible a una "escucha global" (Bejarano, 1978, p. 136). El grupo en su diferenciación intersujetos invoca una participación singular ante cada versión del acontecimiento de intolerancia. Además, al permanecer siempre abierto a nuevos sentidos, confirma que no hay lecturas definitivas. Siguiendo la referencia paradigmática de los abordajes de los textos freudianos, "el lector de Freud es intérprete de un texto que lo sorprende" (Kaës, 1995, p. 35). De igual modo, los lectores de los textos de los testimonios de intolerancia transmiten su impresión de lo inesperado, de lo que surge produciendo asombro. De hecho, el autor del texto inscribe en el mismo su propia sorpresa, pues no esperaba responder del modo en que respondió. Registra en su escritura su sorpresa ante el acontecimiento.

La secuencia de los momentos en el grupo de acontecimiento se muestra en un proceso estratégico. 1. El acontecimiento que se ha instado a escribir es leído por alguien del grupo, alguien que no está predeterminado, pero que debe ser diferente de quien lo escribió. Quien escribe su testimonio de intolerancia no sabe que será leído por otro. Quien lee el testimonio tampoco sabe, antes de empezar a leer, a quién le tocará leer. Se procura inscribir un lugar para la sorpresa allí donde se sitúa la otredad de la lectura. 2. En una segunda sesión, la reescritura del acontecimiento se verifica, de igual modo, como una lectura desde la otredad. El sujeto ya no tiene a su alcance el texto escrito y leído por otro en la primera sesión. Debe reescribirlo en función de la dinámica de grupo que se desenvolvió, es decir, en función de lo que haya escuchado y leído en las intolerancias de los otros. Si existe algo de comprensión, se suscitará desde el otro, desde la escucha y la lectura del otro, esto es, desde la alteridad. 3. En un tercer momento de escritura, después de la apertura discursiva desplegada en las primeras sesiones en torno a los acontecimientos de intolerancia, es el sujeto el que lee aquello que él mismo ha plasmado por escrito. El momento concluye 
asumiendo el acontecimiento mediante su propia lectura.

Nunca se dice lo mismo, nunca se escribe lo mismo. Como el acontecimiento es hecho de dicho, resulta diverso en su testimonio. Las palabras lo hacen transformarse constantemente. $Y$ sus transformaciones involucran la subjetividad de quien está involucrado. Las variaciones del acontecimiento indican así las formas en que la subjetividad se mueve, se moviliza, se construye y descontruye en y a través del discurso grupal. Se apuesta por posicionar el elemento extraño o extranjero en el devenir discursivo del grupo, pues eso, como dice Sibony (1998), "puede despertar la alteridad. Es una promesa. Queda por saber dinamizar la presencia del extraño, que no es en sí misma ni buena ni mala" (p.168). Desenvolvimiento de un trabajo de lo negativo, que A. Green proponía, según lo refiere Neri (2010), superando "las exigencias de adaptación necesarias para participar en la vida comunitaria" (p. 102).

\section{Los testimonios}

Tres componentes de un grupo de acontecimiento, a quienes Ilamaremos Gustavo, Leonel y Xóchitl, abren sus respectivos testimonios de intolerancia. Cada uno escribe tres diferentes versiones sucesivas del mismo testimonio: la primera leída por alguien más en el grupo, la segunda reescrita a partir de la experiencia grupal y la tercera leída por quien la reescribe una vez más. En el segundo y en el tercer caso, la singularidad testimonial estuvo matizada y afectada por el decir de los otros respecto a la propia vivencia de intolerancia. El grupo se constituyó por estudiantes de formación universitaria del sureste de México. Sus integrantes estuvieron de acuerdo en que su testimonio fuera tomado para la transmisión y demostración de un proceso metodológico específico, preservando la identidad de los mismos mediante la modificación de sus nombres propios. Presentamos las tres versiones del acontecimiento tal como fueron escritas por cada uno de sus autores.

\section{Gustavo}

Primera versión. Fue una ocasión cuando un vecino saco (sic) a su perro a propósito para que golpeara al mío, yo no tolere (sic) esta situación y le dije que cuál era su problema y llegamos a los golpes. Entonces estaban peleando nuestros perros y nosotros. Quizá fue un pretexto para desahogarme, ya que tiempo atrás este sujeto me molestaba e insultaba de distintas maneras.

Segunda versión. Esa ocasión cuando me agarré a golpes con mi vecino porque sacó a su perro para que golpeara al mío. No toleré que su perro le pegara a mi perro y lo golpee a él como "desquitándome" de eso y muchas burlas del pasado que me había hecho.

Tercera versión. Cuando mi vecino saco (sic) a su perro para que golpeara al mío, porque era más grande. $Y$ yo le dije que cuál era su problema y no me dijo nada pero se mostró burlón y lo golpee para desquitarme de esa y otras burlas del pasado.

Gustavo y su vecino no sólo participan de una pelea entre sus perros, sino que parece que ellos mismos se pelean como perros. Correlativamente, los perros pelean como si fueran sus dueños: en lugar de morder, el perro del vecino "pega" y "golpea". Es muy significativo, por cierto, que Gustavo responsabilice al vecino del comportamiento de su perro y lo interpele o bien lo desafíe al preguntarle cuál es su problema.

Al principio, en la primera y en la segunda versión, todo parece girar en torno a los perros. La pelea entre los perros, además de asemejarse a una pelea entre sus dueños, termina traduciéndose efectivamente en la pelea entre sus dueños. Luego, en la tercera versión, el pasaje al acto violento figura como una venganza por algo más que los perros. Más que un asunto de perros, parece tratarse de un asunto de burlas. Es la burla del vecino, y no el ataque de su perro, el que desencadena los golpes de Gustavo.

En lugar de que el vecino responda a su pregunta, aparece la burla. $O$ quizás la burla es la respuesta ofensiva a la pregunta. Hasta la tercera versión sale a relucir el virtual argumento acerca de "porque era más grande". No se sabe si se refiere Gustavo a su perro o al perro del vecino. $O$ si se refiere con ello a sí mismo o al vecino. El asunto del tamaño del perro o de los sujetos sitúa una importante diferencia. "Las burlas del pasado" es una frase algo equívoca, pudiendo aludir a que en "el pasado", el que se pasó del límite de tolerancia fuera ese vecino burlón y provocador. 
El pasaje a los golpes cambia un poco de lugar en las tres versiones del escrito. En la segunda versión aparece de inmediato, como consecuencia de que el vecino sacara a su perro con el propósito de golpear al suyo. En la primera versión se llega a los golpes después de la interpelación de Gustavo. Tanto en la segunda como en la tercera versión, es un desquite por las burlas del presente y del pasado. Los golpes, como pretexto de desahogo, se convierten en venganza.

Habría que saber en qué consistían las burlas "del pasado", del vecino, que Gustavo dejó pasar tanto que lo tenían ahogado. Parece una cuestión de confrontación viril, una especie de violencia de supervivencia, como la que describe Wieviorka (2005), donde un sujeto parece "sentirse amenazado en su ser mismo" (p. 299), en este caso, por la mediación o interposición de su perro. Pero ante todo el sujeto se vive intensamente desafiado y ultrajado por otro. El sujeto detecta malignidad intencional en el otro por el mismo hecho de sacar a su perro, como si lo que fuera a sacar resultara ser su burla y su bronca. Quizás se aproxime a algo de lo que Zoja (2013) designa como prisa paranoica, como resultado de una "sospecha exagerada y de la proyección inconsciente largamente contenida" (p. 36). Vislumbramos aquí al menos una prisa por vengarse de las viejas afrentas, un apremio por hacer un violento ajuste de cuentas: un apremio como el que con frecuencia parece convulsionar la relación entre madres e hijas, cuando la madre, a decir de Catalá (1983), reacciona con violencia ante el reclamo de las hijas por no haberlas dotado suficientemente de afecto, palabras, criterio, alimento, símbolos, porque la madre no se apegó estrictamente a su inscripción de "buenas cosas", de "madre-buena cosa", que "se quejan pero se aguantan" (p. 89). La hija exige a la madre que le rinda cuentas de su propia insuficiencia, como si, con ello, la hija exhumara restos de identidad femenina para mitigar su sensación de daño y ultraje.

\section{Leonel}

Primera versión. Desde hace varios años he visto como (sic) mi familia, principalmente mis padres han sido muy intolerantes ante las parejas del mismo sexo. Desde que yo era muy pequeño recuerdo mucho que solía quedarme a jugar con uno de mis primos, me parecía que como al ser alguien mayor podía ser como un modelo a seguir, similar a un hermano (el cual no tengo). Sin embargo, desde hace varios años he visto como (sic) mis padres lo observan y dudan de su orientación sexual, cosa que a mi (sic) no me gustaba, ya que a menudo decían que me parecía a él en aspecto y carácter. Hace poco tiempo sin embargo, resulto ser cierto, ya que mi primo reveló que era homosexual, cosa que en principio no me molestó ni incomodó, hasta que recordé que yo era a vista de los demás muy similar a él. Yo no soy homosexual, pero la actitud de mis padres y de otros hacia él no me agradaban y temía ser víctima de eso o haberlo sido indirectamente en el pasado.

Segunda versión. Recuerdo como (sic) mis padres han sido intolerantes a las relaciones del mismo sexo. Desde hace mucho recuerdo como (sic) solía ir a casa de uno de mis primos mayores a jugar con él. Yo lo veía como si fuera una figura a seguir, ya que no tengo hermanos, sin embargo desde hace tiempo he visto como (sic) mis padres y otros miembros de mi familia dudaban de su sexualidad, lo que no me gustaba. Hace poco sin embargo, mi primo reveló ser homosexual, lo que no me molesta al principio sino hasta que recordé cómo de pequeño me comparaban a él en su carácter y en físico. Temo haber sido víctima de discriminación indirectamente en el pasado y no saberlo y aún más el que la gente crea que lo soy cuando no es así.

Tercera versión. No me gusta la forma en que mis padres u otras personas son intolerantes a las relaciones del mismo sexo. Desde que era pequeño solía ir a jugar a casa de una de mis primos al que yo veía como un modelo a seguir, ya que no tengo hermanos. Pero desde hace tiempo he visto como (sic) mi familia duda de su sexualidad. Hace poco mi primo reveló ser homosexual, lo que no me molesta ni incomoda, hasta que recordé que en el pasado solían compararme mucho con él, por lo que temo que indirectamente haya sido víctima de la misma discriminación a pesar de que no soy homosexual. Temo tal vez ser tratado de la misma forma, con discriminación y rechazo por parte de los demás.

Se advierte el afán de Leonel por enfatizar cómo la carencia de hermanos lo hacía considerar a su primo como un modelo a seguir. Leonel insinúa que ninguno de sus padres resultaba ser ese modelo. Señala su identificación con este primo, aclarando y enfatizando que él no es homosexual como su primo. Es evidente que es intolerante a este tipo de intolerancias que tienen que ver con el rechazo y la discriminación hacia la homosexualidad. Su testimonio ilustra el hecho puntual de que la discriminación comienza frecuentemente en el orden familiar. Y precisamente él, al igual que su primo, ha sido víctima de la misma.

Existe una expresión sobre cierta disposición y actitud familiar que se presta a la equivocidad en 
sus variantes discursivas. En la tercera versión se dice "he visto como mi familia duda de su sexualidad". En la segunda versión de esto que se enuncia se exclama: "he visto como mis padres y otros miembros de la familia dudaban de su sexualidad, lo que no me gustaba". En la primera versión se enuncia algo un poco distinto: "he visto como mis padres lo observan y dudan de su orientación sexual, cosa que a mí no me gustaba". Las frases de la primera y tercera versión son en presente, sólo la segunda es en pasado. La duda persiste, aunque el primo ya se haya revelado homosexual.

Destaca el hecho de que la primera versión, en realidad, combina presente y pasado en relación a estas dudas y su disgusto propio. Estas frases implican las dudas de sus padres y otros miembros acerca de su propia sexualidad; es decir, respecto a la sexualidad de cada uno de ellos. El sujeto mismo llega a develar de algún modo que no le gustaban tanto estas dudas sobre la sexualidad provenientes de su grupo familiar como la orientación sexual de su primo.

\section{Xóchitl}

Primera versión. Me excluyen de una tarea en equipo manifestando que soy una persona que exijo trabajo en equipo, pero presionándolos, dicha situación fue intolerante para mí ya que si bien pedía trabajar a todos en conjunto, así como la colaboración de cada uno de los integrantes; es por el bien de todos, insitó (sic) la participación debido a que es un trabajo en equipo.

Segunda versión. Unas compañeras con quienes venía trabajando desde semestres anteriores, me excluyen de una tarea en equipo manifestando que soy exigente y pido que trabajemos, pero bajo presión, dicha situación fue intolerante para mí, ya que es un trabajo en equipo y se requiere de la colaboración de todos los integrantes, insitó (sic) la participación para que todos aprendamos.

Tercera versión. Unas compañeras con quienes venía trabajando en equipo desde semestres anteriores, me excluyen de una tarea, manifestando que soy una persona exigente y que les presiono, dicha situación fue intolerante para mí, debido a que en un trabajo en equipo se requiere de la colaboración de todos los integrantes y es lo que insitaba (sic), pues si todos participamos, todos aprendemos.

Daniel Sibony (1998) plantea que la exclusión social difiere de la exclusión odiosa en tanto es:
(...) más fría y abstracta, parece resultar de automatismos implacables, sin afectos. Ahora bien, lo que da problema, no es tanto la exclusión, sino que un grupo tenga necesidad de ella, de manera vital. El mecanismo es abstracto, pero funciona como un montaje sacrificial: sacrificar a éstos para que aquéllos estén más cómodos" (p. 205).

Entonces, podemos aseverar que la compañera se considera sacrificada precisamente por instar a la colaboración de todos, por auspiciar lo que se llama un "grupo sofisticado" (Bion, 1985, p. 81), cifrado en el aprendizaje de la experiencia. Compañeras con quienes venía trabajando ya no le toleran su modo de incitar al aprendizaje en grupo. Se dice que incita bajo presión, presionando al grupo, y ella no puede tolerar sus intolerancias. Pero el grupo tampoco puede tolerarla. Resulta revelador que la situación que se narra en las tres versiones sea descrita como "intolerante" y no como "intolerable". Quizás la situación no sea tolerada, pero lo que se dice es que la situación no tiene tolerancia, que no tolera a alguien, quizás a la misma Xóchitl que exige y presiona.

En las dos primeras versiones, se hace una clara distinción entre ser "exigente" o "exigir trabajo en equipo" y hacerlo "bajo presión" o "presionando", como si el problema estribara más bien en el hecho de presionar y no tanto en la exigencia. En cambio, en la tercera versión, el problema engloba "ser una persona exigente y que les presiona". La exigencia termina revelándose tan problemática como la presión. Todo en Xóchitl se torna un problema. $O$ peor: el problema es personal, ya que no se trata de lo que Xóchitl hace, sino de lo que es: una persona exigente y que presiona.

Puede ser que existan en realidad discrepancias en torno a lo que se entienda por trabajar en equipo. Sin embargo, la exclusión social puede comprometer también el odio. Por eso la situación de trabajo colaborativo se traba. ¿Cómo no odiar a aquellos que no trabajan como yo quiero que trabajen? ¿Cómo no odiar a aquel o aquella que nos presiona a trabajar de acuerdo a lo que considera ser lo más correcto? ¿ ¿Cómo no sentir odio hacia aquellos de los que venía siendo elemento colaborador? Es decir, se le deja fuera del grupo porque parece que le 
pide al grupo algo que éste no puede concederle. $Y$ parece que ella no puede colaborar con el grupo sino bajo las condiciones que impone.

Lo que se omitió al principio, en la primera versión, se muestra en las siguientes. Existía una historia de trabajo común. La joven queda también fuera de esa historia. Aunque de igual modo podría tratarse de una situación de impugnación de un liderazgo con características persecutorias. Bejarano (1978) insistía en la importancia de cuestionar la función resistencial del líder colocado en el lugar narcisista de yo ideal.

\section{COMENTARIOS FINALES}

Es importante contrastar y confrontar las distintas versiones de testimonios. Es lo que sugiere Piera Aulagnier (1986) para el abordaje de un caso de psicosis. Se integran las versiones del sujeto, de los padres del sujeto, del analista al ritmo de su escucha y la que se va forjando entre la analista y el sujeto. Todas "serán modificadas parcialmente por las respuestas y las reacciones que cada uno de los narradores teme y espera suscitar en el otro, $y$ en ese tercer oyente que soy yo" (p. 57).

La participación del grupo y del conductor en tanto analista del grupo incide en la modificación de los discursos testimoniales. El grupo ya participa, de hecho, cuando uno de sus componentes da lectura a las primeras dos versiones. Se puntúan y puntualizan esas modificaciones en función de las respuestas y reacciones que suscitan. Como lo sugiere Lacan (1999b): "se trata de situarse en el intervalo de cierta relación entre lo escrito y una intervención hablada que se refiere a él y que en él se apoya" (p. 142). Nos situamos en ese intervalo para que se avizore el horizonte impactante de una posición de intolerancia anudada con una vivencia de violencia.

Los escenarios de la intolerancia son recurrentemente la escuela, la familia, la calle. Escenarios de desenvolvimiento de la violencia. Son espacios donde se resiente el difícil acomodo y tolerancia de las relaciones interhumanas. Cobra relieve esta sentencia que figura en la novela de Manuel Payno (1978), Los Bandidos de Río Frío, de que no hay herida "más enconosa" que la que se inflige al amor propio (p. 320). Esta herida hace que dos personas queden en una disposición, "si no a vengarse, si a desquitarse" (p. 321). Es la "afrenta narcisista" (Freud, 1921-22/2000, p. 217), la cual, siendo tan intolerable, es parte, junto con el duelo y el dolor por la presunta pérdida del objeto, lo que Freud concibe como celos normales. Así nos encontramos con sujetos como Gustavo, afrentado por el vecino en su amor propio y expectante del desquite, 0 como Leonel, herido en su orgullo narcisista porque aquel que era su ideal del yo es discriminado por sus padres - discriminación que la vive como propia-, o como Xóchitl, ultrajada en su amor propio por un grupo de compañeros que, no tolerando su modo y modelo de trabajo, la excluyen y cuestionan su liderazgo.

Lo importante es que se vislumbre que hay más de una perspectiva, más de una manera de ver las cosas. Es por esto que proponemos la escucha y la mediación grupal. Es por lo mismo que, de entrada, el sujeto no leerá él mismo su escrito testimonial de la vivencia de intolerancia, sino que escuchará lo que escribió desde otro lugar, a través de otra boca, en otra voz. Tanto con esta otra voz como con las demás de quienes forman parte del grupo, se pondrá en evidencia que "habrá siempre interpretaciones, distintas contradictorias" (Maalouf, 2010, p. 65).

Los textos que se producen son un esfuerzo de ordenar y reordenar la experiencia misma. Algunos muestran un afán por decir lo imposible, incluso por decir lo imposible que resulta decir exactamente lo mismo. Algunos textos presentan un desenfado y reflejan que no importa mantener y preservar la misma versión del acontecimiento:

No cambian los textos, lo que cambia es nuestra mirada. Pero los textos no actúan sobre las realidades del mundo más que a través de nuestra mirada, que en cada época se fija en determinadas frases y pasa por otras sin verlas (Maalouf, 2010, p. 66).

No obstante, en el Grupo de Acontecimiento, los textos se modifican en las versiones que los constituyen de una sesión a otra. No hay versión mejor o peor, ni 
mejor o peor elaborada, ni más cercana o alejada de la verdad. Es en realidad una interpretación de momento, en función de un punto de detención de la mirada, un foco de tensión, frente a algo que vulneró el amor propio. Entonces lo que se objetiva es cómo la mirada va cambiando en su lectura interpretativa del acontecimiento. Finalmente, es la diversificación de la escucha en una producción de textos donde palpita la realidad de un mundo avasallante del amor propio.

La multiplicidad de la escucha en el Grupo de Acontecimiento involucra un doble papel en el componente del grupo, un doble movimiento transferencial. El sujeto lee y es leído, escucha y es escuchado, en un deslizamiento constante de la palabra. En su doble función de creador y lector de textos, la emergencia de la equivocidad, como lo vimos en los testimonios, permite "hacer resonar el equívoco en el cuerpo para tocar el síntoma" (Morel, 2012, p. 119). En el cuerpo del grupo y en grupo como cuerpo que so-porta varios síntomas, se plasma una resonancia del significante equívoco, de la frase equívoca, de eso que, en su corte enunciativo, declara que es posible un plus de interpretación. La imagen del cuerpo es propuesta por Kaës (1990) como uno de los organizadores psíquicos de la "representación del objeto-grupo" (p. 91) que hacen posible que la palabra circule a través de cada uno de los miembros, articulándose o desarticulándose, modificándose su sentido e impacto. En lo sincrónico de la participación asociativa del grupo, se puede ofrecer otra narrativa del pasado, del acontecimiento como advenimiento de intolerancia, hacerlo "legible de otro modo, nuevo" (Zizek, 2012, p. 88).

\section{ASPECTO ÉTICO (CONSENTIMIENTO INFORMADO)}

Los y las participantes en el Grupo de Acontecimiento fueron consultados y consultadas sobre su disposición a participar en una experiencia en la cual sus testimonios fueran requeridos con fines investigativos para dar cuenta de su composición discursiva y alcance subjetivo. De manera verbal hicieron saber su aceptación y se acordó con ellos y ellas que sus nombres serían modificados. Se trata de estudiantes universitarios que deliberadamente admitieron y estuvieron abiertos a la posibilidad de que sus discursos fueran tomados en sus diversas versiones para estudio científico. El trabajo de intervención se llevó a cabo en la Universidad Ciencias y Artes del Estado de Chiapas en noviembre de 2015 con estudiantes de dicha institución. Los que tuvieron interés en participar en dicha experiencia propuesta bajo la modalidad de taller y aceptada por los organizadores en el marco del evento de la Segunda Sesión de la Cátedra CUMEX (Consorcio de Universidades Mexicanas) en Psicología de 2015. Dicho grupo de acontecimiento se presentó bajo el nombre de "Trabajando las intolerancias en grupo".

\section{CONTRIBUCIONES DE LOS AUTORES}

1. Investigación. El grupo de acontecimiento fue creado, coordinado y conducido por el Dr. Mario Orozco Guzmán con el apoyo de observación de la Mtra. Verónica Arredondo Martínez. El trabajo de análisis de sus datos testimoniales fue llevado a cabo en este trabajo por el coordinador del grupo, la Dra. Flor de María Gamboa Solís, y el Dr. David Pavón Cuéllar (integrantes del Cuerpo Académico de la Universidad Michoacana de San Nicolás de Hidalgo "Estudios sobre teoría y clínica psicoanalítica").

2. Artículo. El Dr. Mario Orozco Guzmán aportó la línea teóricoargumentativa para el análisis de los hallazgos, así como el diseño metodológico. La Dra. Flor de María Gamboa Solís contribuyó con contenido intelectual crítico. El Dr. David Pavón Cuéllar aportó ideas y reflexiones críticas en el análisis del material discursivo que sostiene los hallazgos, y editó la última versión del manuscrito. El Dr. Mario Orozco Guzmán, la Dra. Flor de María Gamboa Solís y el Dr. David Pavón Cuéllar escribieron el manuscrito.

\section{COMPETING INTERESTS}

No financial, legal or political competing interests with third parties (government, commercial, private foundation, etc.) were disclosed for any aspect of the submitted work (including but not limited to grants, data monitoring board, study design, manuscript preparation, statistical analysis, etc.).

\section{REFERENCIAS}

Aulagnier, P. (1986). El aprendiz de historiador y el maestro-brujo. Del discurso identificante al discurso delirante. Buenos Aires: Amorrortu.

Barthes, R. (2009). Diario de duelo. 26 de octubre de 1977-15 de septiembre de 1979. México: Siglo XXI.

Bejarano, A. (1978). Resistencia y transferencia en los grupos. In 
D.Anzieu et al. El trabajo psicoanalítico en los grupos. México: Siglo XXI.

Bion, W. (1985). Experiencias en grupos. Barcelona: Paidós.

Catalá, M. (1983). Reflexiones desde un cuerpo de mujer. Barcelona: Anagrama.

Cixous, H. Y, Clément, C. (1986). The newly born woman. Minneapolis: University of Minnesota Press.

Copjec, J. (2006). El sexo y la eutanasia de la razón. Ensayos sobre el amor y la diferencia. Buenos Aires: Paidós.

De Beauvoir, S. (1949). El segundo sexo. México: Debolsillo, 2012.

Flax, J. (1990). Psicoanálisis y feminismo. Pensamientos fragmentarios. Madrid: Cátedra.

Frank, A. (2001). El diario de Ana Frank. México: Leyenda.

Freud, S., \& Brever, J. (2000). Estudios sobre la histeria. (J. Strachey, Ed., Etcheverry, J.L., Trans.) Sigmund Freud Obras completas (2nd ed., Vol. 2). Buenos Aires: Amorrortu. (Original work published in 1893)

Freud, S. (2000). Tótem y tabú. In J. Strachey (Ed.), Etcheverry, J.L. (Trans.), Sigmund Freud Obras completas, 13, 1-164. Buenos Aires: Amorrortu. (Original work published in 1913)

Freud, S. (2000). Sobre algunos mecanismos neuróticos en los celos, la paranoia y la homosexualidad. In J. Strachey (Ed.), Etcheverry, J.L. (Trans.), Sigmund Freud Obras completas, 18, 213-226). Buenos Aires: Amorrortu. (Original work published in 1921)

Greiser, I. (2012). Psicoanálisis sin diván. Los fundamentos de la práctica analítica en los dispositivos jurídico-asistenciales. Buenos Aires: Paidós.

Irigaray. (1977). Ese sexo que no es uno. Barcelona: Akal, 2009.

Kafka, F. (2011). Carta al padre. México: Manantial

Kaës, R. (1995). El grupo y el sujeto del grupo. Elementos para una teoría psicoanalítica del grupo. Buenos Aires: Amorrortu.

Kaës, R. (1990). El aparato psíquico grupal. Construcciones de grupo. Barcelona: Granica.

Kant, E. (1991). Crítica del Juicio. México: Porrúa. (Trabajo original publicado en 1790)

Lacan, J. (2001). Aun. Buenos Aires: Paidós.

Lacan, J. (1981). Los escritos técnicos de Freud. Buenos Aires: Paidós.

Lacan, J. (1986). Le séminaire. Livre VII. L'éthique de la psychanalyse. París: Seuil.
Lacan, J. (1999a). Fonction et champ de la parole et du langage en psychanalyse. En Écrits I (pp. 235-321). París: Seuil Poche.

Lacan, J. (1999b). El reverso del psicoanálisis. Buenos Aires: Paidós.

Maalouf, A. (2010). Identidades asesinas. Madrid: Alianza editorial.

Malraux, A. (1979). La condición humana. México: Seix Barral.

Aurelio, M. (2000). Meditaciones. Madrid: Debate.

Milmaniene, J. E. (2010). Clínica de la diferencia en tiempos de perversión generalizada. Buenos Aires: Biblos.

Morel, G. (2012). La ley de la madre. Ensayo sobre El sinthome sexual. Santiago de Chile: Fondo de Cultura Económica.

Neri, C. (2010). Trouble narcissique et pacte dénégatif. In $M$. Pichon, H. Vermorel \& R. Kaës (Comp.), L'experience du groupe. Approche de l'oeuvre de René Kaës. (pp. 93114 ). Paris: Dunod.

Pavón-Cuéllar, D. (2013). De la palabra al acontecimiento: límites, posibilidades y desafíos del análisis lacaniano de discurso. En I. Parker y D. Pavón-Cuéllar (Coord.), Lacan, discurso, acontecimiento: nuevos análisis de la indeterminación textual (pp. 389-404). Ciudad de México: Plaza y Valdés.

Payno, M. (1983). Los bandidos de Río Frío. México: Porrúa.

Pichon-Riviere, E. (1978). El proceso grupal. Del psicoanálisis a la psicología social. Buenos Aires-Nueva Visión.

Sibony, D. (1998). Violence. París: Seuil.

Vigarello, G. (2004). Histoire de la beauté. Le corps et l'art d'embellir de la Renaissance a nos jours. París: Seuil.

Vinaccia, S., Fernández, H., Amador, O., Tamayo, R., Vásquez, A. (2005). "Calidad de vida, ansiedad y depresión en pacientes con diagnóstico de síndrome de colon irritable". Terapia psicológica, 23(2), 65-74.

Wieviorka, M. (2005). La violence. París: Hachette.

Woolf, V. (1929). Un cuarto propio. México: Colofón.

Zizek, S. (2012). El sublime objeto de la ideología. México: Siglo XXI.

Zoja, L. (2013). Paranoia. La locura que hace la historia. Buenos Aires: Fondo de Cultura Económica. 